\title{
Hepatic and Cardiac Complications related to Zika Virus Infection
}

\author{
Hassan Naji
}

\begin{abstract}
Major global concerns regarding Zika virus (ZIKV) infection, include microcephaly in neonates and Guillain-Barre syndrome in adults. However, there is evidence for the involvement of other body organs along with neurological disorders. Recent studies indicate that ZIKV like other arboviruses can cause cardiovascular complications, severe liver injury, and coagulation disorders. These possible threats must not be overlooked, and clinicians should be aware of compatible symptoms in patients, so they can manage them properly. The purpose of this review study is to characterize hepato-cardiac complications of Zika virus.
\end{abstract}

Index Terms-Zika Virus, ZIKV, Cardiac Complications, Hepatic Complications, Hepato-Cardiac Complications, Microcephaly, Congenital Disorders, Flavivirus, GuillianBarre Syndrome, Aedes Spp.

\section{INTRODUCTION}

Zika virus was first identified in the blood of a sentinel rhesus monkey in the Zika Forest in Entebbe, Uganda in 1947 (Rather, Lone, Bajpai, Park, \& Park, 2017). Later, the virus was discovered in human among field workers, and then spread to other individuals in Asia and Africa but continued to remain insignificant for over six decades. Zika virus was first isolated in humans in 1952 (Rather et al., 2017). It was overlooked before 1952 because only $20 \%$ of patients developed a self-limited acute febrile illness with mild symptoms including fever, sore throat, myalgias, conjunctivitis, and maculopapular rash, that resolved within 1-2 weeks. The remaining patients infected with the virus were asymptomatic (Rasmussen, Jamieson, Honein, Ph, \& Petersen, 2016).

Zika virus (ZIKV) is a small, enveloped, single positive stranded RNA arbovirus that belongs to the Flavivirus genus of the Flaviviridae family. ZIKV is approximately $11 \mathrm{~kb}$ positive-sense RNA virus. Virions of Zika virus are 40-60 $\mathrm{nm}$ in diameter, spherical in shape and are enclosed in a lipid envelope. The RNA strand of the virus contains 10794 nucleotides which encode 3419 amino acids and contains two flanking untranslated regions and a single long open reading frame which encodes a polyprotein (Chen \& Hamer, 2016). Other mosquito-borne important flaviviruses are yellow fever virus and dengue virus, etc. (Chan, Choi, Yip, Cheng, \& Yuen, 2016). ZIKV has two families: African and Asian. In 2007, an epidemic was generated by the Asian family of ZIKV on Yap Island, Micronesia; it then spread to French Polynesia and other regions of the South Pacific and led to epidemics in 2013 and 2014; following this ZIKV

Published on July 8, 2019.

H. Naji is with Purdue University, Northwest, Hammond, Indiana, USA (e-mail: hnaji@pnw.edu) came to the Americas in 2015, causing an estimated 1.5 million cases in Brazil in 2015 (Shan et al., 2016).

In recent years, severe neurotropic complications including microcephaly in newborns and Guillain-Barre syndrome in adults have been reported in ZIKV-infected individuals. Additionally, some unusual clinical symptoms and signs including transient hearing loss, retinal lesions, severe abdominal discomfort, vomiting, cardiovascular complications, liver injury, and coagulation disorders were also observed in patients with ZIKV infection. It suggests that apart from neurological complications, there is also hepato-cardiac complications associated with Zika virus (Wu et al., 2017). This review paper categorizes hepatic and cardiac complications of zika virus infection.

\section{TRANSMISSION}

Zika virus is transmitted by Aedes spp. Mosquito. Rhesus monkey can be the source of human infections through the bite of Ae. aegypti and Aedes albopictus in infected monkeys and subsequently transmitted to human hosts. These mosquitoes are similar to those that transmit dengue and yellow fever (Nhan \& Musso, 2015). The most substantial vector for ZIKV is Aedes mosquitoes; however, some Anopheles, Culex, Mansonia and Eretmapodites species have also been suggested as vectors (Cao-Lormeau et al., 2016). ZIKV transmission is also believed to occur through sexual activities. It can also be transmitted from placenta and through placental transplant (Besnard, Lastère, Teissier, Cao-Lormeau, \& Musso, 2014). It can also be transmitted through blood transfusions (Venturi et al., 2016). Another route of transmission of ZIKV is monkey bite. Such a case was reported in Indonesia. There is also suspicion of the spread of ZIKV through breastfeeding (Bradford, 2016). The virus has been detected in semen, urine, and saliva (Kim \& Shresta, 2016).

\section{EPIDEMIOLOGY}

The world health organization established that the first case of ZIKV infection in human history was discovered in 1952 in Nigeria. It was thought that the virus is an issue only in Africa and some parts of Asia. However, in 2007, due to the pandemic befell Micronesia and Island in the State of Yap with over 5000 infections in a population of 6700 , changed this idea. Another outbreak of the infectious virus was reported in 2013 and 2014 in French Polynesia. Other cases are also reported in 2014 in Pacific Islands like in Cook Islands, Samoa, and American Samoa (Rather et al., 2017). The existence of the virus in America was reported in March, 2015, during the outbreak of an exanthematous 
illness that occurred in Bahia, Brazil (Campos, Bandeira, \& Sardi, 2015). In December, 2015, the reported cases of ZIKV infection by Brazil Ministry of Health culminated to 1.3 million (Hennessey, Fischer, \& Staples, 2016). The virus was initially discovered from the amniotic fluid of two Brazilian women and later the fetuses were also positive for ZIKV infection. An extensive research commissioned by the Brazil Ministry of Health examined that how the mothers of infected fetuses with microcephaly might have been affected by living or visiting countries with ZIKV infection. The same results were obtained from the 35 participated infants during the study (Schuler-Faccini et al., 2016).

\section{REVIEW}

\section{A. Methodology}

Research methodology include publication researches, interviews, surveys and other historical information on the cardiac and hepatic involvement of Zika virus. All this data was part of our inclusive criteria. This research paper focuses on in-depth analysis of data provided through publications and aims at creating a meta-analysis of Zika complications specifically pertaining involvement in the heart and liver.

Each publication was evaluated based on hepatic and cardiac involvement of zika virus infection. The assessments on the publications were made on formerly stated eligibility criteria. Full texts of publications were extracted for further evaluation. The summaries of our findings are included in table 1.

TABLE I: SUMMARY OF THREE STUDIES

\begin{tabular}{|c|c|c|c|c|c|c|c|}
\hline Study & Study Type & First Author & $\begin{array}{l}\text { Country of } \\
\text { Author (Year of } \\
\text { Publication) }\end{array}$ & $\begin{array}{l}\text { No. of } \\
\text { specimen }\end{array}$ & $\begin{array}{l}\text { Virus } \\
\text { Inoculated }\end{array}$ & $\begin{array}{l}\text { Organ } \\
\text { involved }\end{array}$ & Relevant tests done \\
\hline 1. & Case report & Schwartzman & Brazil (2017) & 1 & No & Heart & $\begin{array}{l}\text { Laboratory tests and microbiological } \\
\text { investigations, autopsy, electron } \\
\text { microscopy, immunohistochemistry, } \\
\text { immunofluorescence }\end{array}$ \\
\hline 2. & Case report & Yanhua Wu & China (2017) & 1 & Yes & Liver & $\begin{array}{l}\text { Complete blood count, liver enzymes, } \\
\text { fibrinogen level, fibrinogen degradation } \\
\text { products, creatine kinase level, } \\
\text { immunofluorescence, genome sequencing } \\
\text { of ZIKV }\end{array}$ \\
\hline 3. & $\begin{array}{l}\text { Observational } \\
\text { prospective multi- } \\
\text { center study }\end{array}$ & Carta KA & $\begin{array}{l}\text { Venezuela } \\
(2017)\end{array}$ & 9 & No & Heart & $\begin{array}{l}\text { Echocardiogram, laboratory studies, } \\
\text { CMRI, Holter monitoring, ECG }\end{array}$ \\
\hline 4. & Case report & Willmar & Colombia (2017) & 2 & No & Heart & ECG, echocardiogram, Zika-RT-PCR \\
\hline
\end{tabular}

CMRI: Cardiac Magnetic Resonance Imaging, ECG: Electrocardiogram

\section{RESUlts}

The literature search exposed a number of relevant studies on hepatic and cardiac complications of Zika virus infection. In this paper we reviewed four studies; three of the studies are case reports and the last one is an observational prospective multi-centered study by (K.A.G. et al., 2017). A fatal case of an adult patient receiving immunosuppressive drugs following heart transplant was reported in Brazil (Schwartzmann et al., 2017). A case of a zika virus infected 29 years old Chinese man, who upon returning from a business trip to Cambodia was bitten by a mosquito and was infected with zika virus (Wu et al., 2017). The last case reviews information on 2 pregnant females who were infected with zika virus and developed cardiovascular complications (Villamil-Gómez, Ramirez-Vallejo, \& Rodriguez-Morales, 2018). The number of cases exposed to the virus added up to 13 including 8 females and 5 males.

\section{A. Study 1}

A 36-year-old man was admitted to Clinic Hospital of Ribeirão Preto, eight months following a heart transplant due to Chagas cardiomyopathy. The patient presented with a 2-day history of high-grade fever, headache, malaise, and seizures (Schwartzmann et al., 2017). Before hospitalization, the patient was receiving standard immunosuppression after a heart transplant. He was hemodynamically stable and had no meningeal signs.
Magnetic resonance imaging (MRI) was done on the patient for the differential diagnosis. The magnetic resonance imaging (MRI) revealed a low apparent diffusion coefficient and low cerebral blood flow with cytotoxic cortical edema surrounded by vasogenic edema, hyperintense on T2-weighted imaging and fluid attenuated inversion recovery. Cerebrospinal fluid (CSF) examination revealed 2 cells/ $\mu 1$, a high protein level and a normal glucose level. The RT-PCR results from CSF were positive for ZIKV infection. The patient still had 3 to 4 daily episodes of fever $\left(37.8^{\circ} \mathrm{C}-38.4^{\circ} \mathrm{C}\right)$ and had progressive worsening of neurologic symptoms, after 1 week of hospitalization. On the 10th day of hospitalization, atrial fibrillation occurred, and cardiac rejection was suspected. Subsequently, the patient had signs of low cardiac output with worsening peripheral blood perfusion and elevated plasma lactate levels. Despite inotropic therapy with dobutamine, the patient experienced refractory circulatory shock followed by cardiac arrest with pulseless electrical activity and died. The cause of death was cardiogenic shock due to acute cardiac allograft rejection.

Autopsy studies revealed that the heart was enlarged $(630 \mathrm{~g})$ with a moderate amount of inflammatory infiltrate of mononuclear predominance, rich in plasma cells permeating through the muscle fibers mainly around the vessels with aggression to the vascular endothelium, compatible with acute cardiac cellular rejection. 


\section{B. Study 2}

A 29-year-old healthy Chinese man after returning from a 7-day business trip to Cambodia, claimed to have been bitten by a mosquito in Cambodia. The patient experienced high fever $\left(40.4^{\circ} \mathrm{C}\right)$, chills, sore throat, fatigue and myalgia (Wu et al., 2017). His serial blood samples were obtained for routine clinical laboratory tests, and identification of specific pathogens. The tests confirmed that the patient had ZIKV infection. Concomitantly, he was showed clinical signs of severe liver injury and coagulation disorders.

TABLE II: CHANGES OF PARAMETERS OF BLOOD ROUTINE TESTS IN THE

\begin{tabular}{lllllllll}
\hline \hline & $\begin{array}{l}\text { D6 } \\
*\end{array}$ & $\begin{array}{l}\text { D7 } \\
*\end{array}$ & D8* & D9* & $\begin{array}{l}\text { D10 } \\
*\end{array}$ & $\begin{array}{l}\text { D11 } \\
*\end{array}$ & $\begin{array}{l}\text { D12 } \\
*\end{array}$ & $\begin{array}{l}\text { Referenc } \\
\text { e value }\end{array}$ \\
\hline $\begin{array}{l}\text { WBC } \\
\left(\times 10^{9}\right)\end{array}$ & $\begin{array}{l}2.2 \\
8\end{array}$ & $\begin{array}{l}3.0 \\
0\end{array}$ & 6.83 & 6.98 & 5.13 & 4.72 & 3.55 & $3.5 \sim 9.5$ \\
\hline $\begin{array}{l}\text { NE } \\
\left(\times 10^{9}\right)\end{array}$ & 1.3 & 1.3 & 2.96 & 2.55 & 1.96 & 1.86 & 1.64 & $1.8 \sim 6.3$ \\
\hline $\begin{array}{l}\text { LY } \\
\left(\times 10^{9}\right)\end{array}$ & 0.8 & 1.0 & 3.26 & 3.52 & 2.54 & 2.42 & 1.35 & $1.1 \sim 3.2$ \\
\hline $\begin{array}{l}\text { MO } \\
\left(\times 10^{9}\right)\end{array}$ & 0.0 & 0.5 & 0.41 & 0.62 & 0.50 & 0.39 & 0.28 & $0.1 \sim 0.6$ \\
\hline $\begin{array}{l}\text { EO } \\
\left(\times 10^{9}\right)\end{array}$ & 0 & 0.0 & 0 & 0.04 & 0.01 & 0.03 & 0.01 & $0.02 \sim 0.5$ \\
\hline BAS & 0.0 & 0.0 & 0.16 & 0.19 & 0.09 & 0.02 & 0.04 & $0 \sim 0.06$ \\
$\begin{array}{l}\text { O } \\
\left(\times 10^{9}\right)\end{array}$ & 2 & 8 & & & & & & \\
\hline $\begin{array}{l}\text { RBC } \\
\left(\times 10^{12}\right.\end{array}$ & 5.0 & 4.5 & 5.23 & 4.49 & 4.7 & 4.56 & 4.44 & $4.00 \sim 5.5$ \\
) & 9 & & & & & & 0 \\
\hline $\begin{array}{l}\text { HGB } \\
(\mathrm{g} / \mathrm{L})\end{array}$ & 148 & 140 & 163. & 139. & 146. & 134. & 137 & $120 \sim 160$ \\
\hline \hline
\end{tabular}

WBC = white blood cell; RBC = red blood cell; HGB = hemoglobin; LY = lymphocytes; $\mathrm{MO}=$ Monocyte; NE = Neutrophils; $\mathrm{EO}=$ eosinophils; $\mathrm{BASO}=$ basophilic granulocyte. ${ }^{*}$ Days post fever onset.

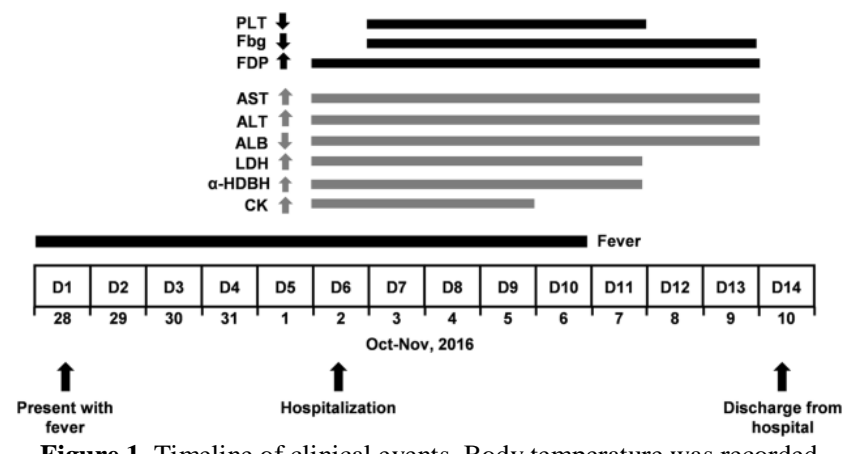

Figure 1. Timeline of clinical events. Body temperature was recorded daily. Changes of parameters reflecting coagulation and liver function were determined by routine blood examination and biochemistry tests from D6 to being discharged from the hospital.

Results showed that his total white blood cell counts were transiently decreased on D6 and D7. WBC returned to normal range on D10. Several parameters reflecting tissue or organ damage were also recorded. During the entire period of hospitalization, the patient had significantly elevated levels of aspartate aminotransferase (AST) (122.4-511.7 $\mathrm{U} / \mathrm{L}$ ), alanine aminotransferase (ALT) (225.8-329.6 U/L), lactic dehydrogenase (LDH) (909-1433 U/L) and alphahydroxybutyric dehydrogenase ( $\alpha-\mathrm{HDBH})(792-931 \mathrm{U} / \mathrm{L})$, but reduced albumin (ALB) concentrations (31.9-39.3 g/L). On D6 to D9, increased creatine kinase (CK) level (792-937 U/L) was also observed. These results indicate serious tissue injury, especially liver damage.

Concomitantly, blood coagulation parameters showed marked alterations: the platelet count decreased suddenly to
$22 \times 109$ platelets/L on D7 and remained at low levels between $20 \times 109 / \mathrm{L}$ and $63.4 \times 109$ platelets/L during D8 to D11. It returned to normal range on D13. These changes are indicative of abnormal blood coagulation and anticoagulation pathways in the patient, although he had no obvious clinical sign of bleeding. ZIKV was isolated by sequential passage in $\mathrm{C} 6 / 36$ cells and named ZIKVCCMU01. The blood culture was also negative for bacteria and fungus. These results were consistent with an interpretation that most manifested symptoms in this individual were a direct consequence of ZIKV infection.

\section{Study 3}

In this prospective observational multicenter study, all 9 participants, mean age $47 \pm 17$ years, with no prior history of cardiac disease, were followed for an average of 6 months, beginning in July 2016 in Venezuela (K.A.G. et al., 2017). All but 1 patient developed a dangerous heart rhythm and two-thirds had evidence of heart failure. Electrocardiogram studies of the patients revealed that 8 patients had an issue with the rate or rhythm of heartbeat. Investigations of a full cardiovascular work-up using an echocardiogram, a 24-hour Holter monitor, and cardiac magnetic resonance imaging revealed 3 cases of atrial fibrillation, 2 cases of non-sustained atrial tachycardia, and 2 cases of ventricular arrythmias. Out of 6 cases of heart failure, 5 patients had heart failure with preserved ejection fraction along with preeclampsia and moderate to severe pericardial effusion.

\section{Study 4}

This case study involves 2 pregnant women infected with ZIKV who presented with cardiovascular and electrocardiographical (ECG) alterations (Villamil-Gómez et al., 2018). One of the women was 30 years, at gestational week 34.2 and the other was 25 years at gestational week 10.1 . Both women presented with rash and pruritus and the RTPCR was positive for ZIKV. Cardiac enzymes for both women were negative. The ECG for the first woman showed a sinusal tachycardia with a prolonged QTc (associated with Torsade de Pointes) (using Bazett formula) and at the echocardiogram, $200 \mathrm{cc}$ of pericardial fluid was found. She had not presented with cardiovascular disease earlier.

The ECG of the other woman showed a left anterior hemiblock and at the echocardiogram, $300 \mathrm{cc}$ of pericardial fluid was found. She also had not presented with cardiovascular disease earlier. After 2 weeks, ECGs and echocardiograms of both women were normal.

\section{DISCUSSION}

Zika virus infections occasionally causes neurotropic disorders (e.g. meningoencephalitis, acute myelitis, and Guillain-Barre syndrome) and congenital birth defects such as neonatal microcephaly and congenital zika syndrome (Rogéria et al., 2016). Patients with ZIKV reported with a clinical picture resembling other flaviviruses like dengue fever, West Nile virus, yellow fever virus, Japanese encephalitis virus, and tick-borne encephalitis virus. Therefore, it can easily be misdiagnosed. (Tappe et al., 2014). It is transmitted by Aedes sp. mosquitoes. The acute 
hemorrhagic fever can be the first presentation of Zika virus infection. The most common manifestations of Zika virus include fever, headache, myalgia, conjunctivitis, pruritis, and fatigue, which are similar to that of dengue fever. In this review, it is suggested that apart from these signs and symptoms, ZIKV can also present with some unusual symptoms like hearing loss, severe abdominal pain, cardiac and hepatic complications. With such vast symptoms and complications of $\mathrm{ZIKV}$, there is a dire need to further determine the harms that can be caused by ZIKV.

The 13 cases in our study are suggestive of the fact that apart from the classical picture of ZIKV infection, there is hepato-cardiac involvement also. This fact is helpful in cases in which the person is asymptomatic and has travelled to areas prone to Zika virus. These include Aruba, Barbados, Bolivia, Brazil, Colombia, Costa Rica, Cuba, Ecuador, Mexico, Guatemala, Haiti, Panama, Trinidad and Tobago, and American Samoa among others (Hsieh, 2017).

The first case shows that ZIKV infection in immunocompromised patients can lead to severe organ dysfunction such as in the heart. However, the relationship between ZIKV with death and organ dysfunction in immunocompromised patients is not yet clear.

Previously, it was thought that ZIKV is majorly associated with neurological and congenital disorders including microcephaly and congenital zika syndrome, in neonates whose mothers were exposed to zika virus during gestational period (Besnard, Lastère, Teissier, \& Musso, 2014). During January 1, 2016 to April 25, 2017, U.S. territories reported 2549 completed pregnancies with local transmission of zika virus infection. The infection was confirmed with laboratory evidence; $5 \%$ of fetuses or infants resulting from these pregnancies had birth defects possibly associated with Zika virus infection. Among infants with live birth, 59\% had Zika virus infection (Shapiro-Mendoza et al., 2017). Interestingly, Villamil-Goméz et al reported 2 cases of pregnant women suggesting Zika virus can affect the heart during pregnancy as depicted by electrocardiographic changes and pericardial effusion by electrocardiogram, without clinical manifestations of cardiac involvement. This fact is specifically important since cardiovascular complications are the most important cause of mortality during pregnancy (Gongora \& Wenger, 2015).

Furthermore, Brasil, et al. formulated in their study that there is an association between congenital heart disease in infants born to Zika virus infected mothers (P. et al., 2016). There is a need for the identification and follow-up of infants born to women with laboratory evidence of possible Zika virus infection during pregnancy (Shapiro-Mendoza et al., 2017).

The observational prospective and multi-centered study done in Venezuela was the first to report a link between heart problems and Zika virus infection. This study suggests that a person who travels to or lives in a place with known Zika virus and develops fever, rash, or conjunctivitis, and within a few days feels other symptoms such as fatigue, shortness of breath, or other heart skipping beats, then the person should see a doctor as the virus can lead to rapidly progressive heart failure and arrythmias. The symptoms of the cardiac issues can be improved by guide-line directed treatment for atrial fibrillation or heart failure. There is a still a need for larger, systematic studies to understand the actual risk of Zika-related cardiac disorders (K.A.G. et al., 2017).

Similarly, a case was reported in China in which the patient was previously healthy with no prior history of liver disease and blood disease. After being infected with Zika virus, he ha chronically elevated levels of ALT and AST as well as low ALB levels indicating liver injury. Specifically, his AST and ALT levels were 12.8 and 6.6 times higher than the upper limits of their respective normal values. This was the first report of ZIKV infection involving liver damage.

Moreover, significantly increased serum levels of $\mathrm{LDH}$, $\mathrm{CK}$, and $\alpha$-HDBH were also observed. These enzymes are normally present in blood cells, heart muscles, and hepatocytes, and they are the markers of heart and liver injury. Coagulation disorder was also observed in this patient, manifested by low platelet count, decreased fibrinogen and elevated FDP levels. Fibrinogen is a blood clotting protein and is converted into fibrin from thrombin during clot formation. FDP are produced due to the breakdown of plasmin. Increased levels of fibrinogen indicate hemorrhagic complications. Thus, Zika virus can lead to coagulopathy which can cause bleeding ( $\mathrm{Wu}$ et al., 2017).

Since the beginning of Zika virus epidemic in America, several cases with thrombocytopenic complications in Zika virus infection were reported (Chammard et al., 2017). In the most severe cases the platelet count was as low as $1 \times 10^{9}$ or $2 \times 10^{9}$ platelets/L. however, some patients had prior history of obesity, hypertension, hyperlipidemia, acute immune mediated thrombocytopenia, or 7-month-pregnancy (Chraïbi et al., 2016). In contrast, this patient was previously healthy.

Zika virus disease can present with similar clinical symptoms of other flaviviruses. Moreover, elevated transaminases and thrombocytopenia are suggestive of liver damage and there is a need for differential diagnosis of Zika virus from other flaviviruses (Ioos et al., 2014). 


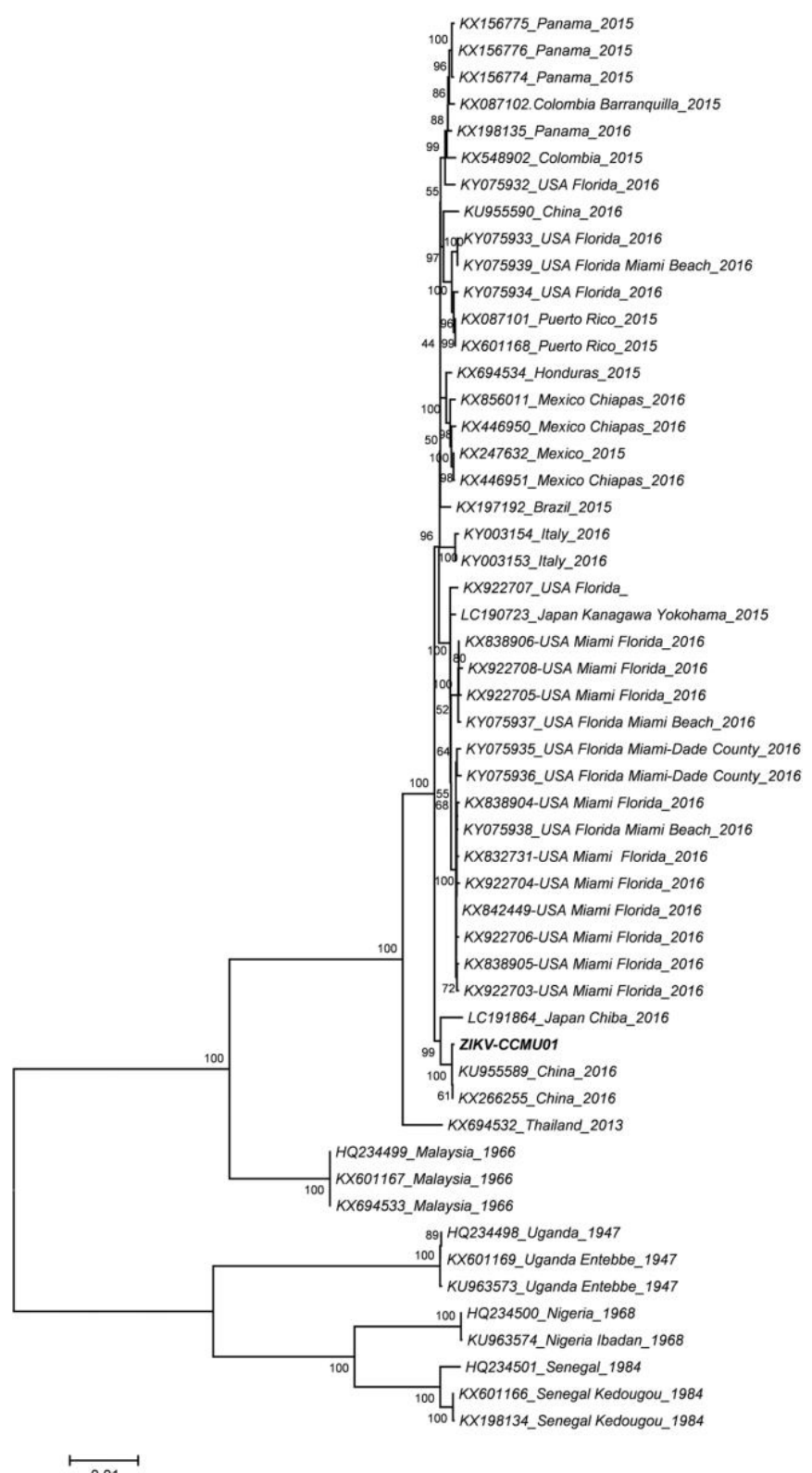

Fig. 2. Phylogenetic analysis of Zika viruses. Phylogeny tree of the whole genome of ZIKV-CCMU01 and other 52 ZIKV strains registered in GenBank were constructed by Neighbor-joining method using MAGE 5 software.

\section{CONCLUSION}

In this review, an effort is made to disclose the link between ZIKV infection and hepato-cardiac complications. Therefore, clinicians should not only be aware of neurological manifestations of zika virus, but also pay attention to the dysfunction of other organs such as heart and liver. Further study is needed to demonstrate long-term effects of Zika virus infection on the functioning of major organs of the body.

\section{REFERENCES}

Besnard, M., Lastère, S., Teissier, A., Cao-Lormeau, V. M., \& Musso, D. (2014). Evidence of perinatal transmission of zika virus, French Polynesia, December 2013 and February 2014. Eurosurveillance. https://doi.org/10.2807/1560-7917.ES2014.19.13.20751

Besnard, M., Lastère, S., Teissier, A., \& Musso, D. (2014). Evidence of perinatal transmission of Zika virus, French Polynesia, December 2013 and February 2014. (December 2013), 8-11.
Campos, G. S., Bandeira, A. C., \& Sardi, S. I. (2015). Zika Virus Outbreak, Bahia, Brazil. Emerging Infectious Diseases. https://doi.org/10.3201/eid2110.150847

Cao-Lormeau, V. M., Blake, A., Mons, S., Lastere, S., Roche, C. Vanhomwegen, J., ... Ghawché, F. (2016). Guillain-Barré Syndrome outbreak caused by ZIKA virus infection in French Polynesia Europe. Lancet. https://doi.org/10.1016/S0140-6736(16)00562-6

Chammard, T. B., Schepers, K., Breurec, S., Messiaen, T., Destrem, A. L., Mahevas, M., ... Hoen, B. (2017). Severe thrombocytopenia after zika virus infection, guadeloupe, 2016. Emerging Infectious Diseases. https://doi.org/10.3201/eid2304.161967

Chan, J. F. W., Choi, G. K. Y., Yip, C. C. Y., Cheng, V. C. C., \& Yuen, K Y. (2016). Zika fever and congenital Zika syndrome: An unexpected emerging arboviral disease. Journal of Infection. https://doi.org/10.1016/j.jinf.2016.02.011

Chen, L. H., \& Hamer, D. H. (2016). Zika Virus: Rapid Spread in the Western Hemisphere. Annals of Internal Medicine. https://doi.org/10.7326/m16-0150

Chraïbi, S., Najioullah, F., Bourdin, C., Pegliasco, J., Deligny, C., Résière, D., \& Meniane, J. C. (2016). Two cases of thrombocytopenic purpura at onset of Zika virus infection. Journal of Clinical Virology. https://doi.org/10.1016/j.jcv.2016.08.299

Gongora, M. C., \& Wenger, N. K. (2015). Cardiovascular complications of pregnancy. International Journal of Molecular Sciences. https://doi.org/10.3390/ijms161023905

Hennessey, M., Fischer, M., \& Staples, J. E. (2016). Zika Virus Spreads to New Areas - Region of the Americas, May 2015-January 2016. American Journal of Transplantation. https://doi.org/10.1111/ajt.13743

Hsieh, Y.-H. (2017). Temporal patterns and geographic heterogeneity of Zika virus (ZIKV) outbreaks in French Polynesia and Central America. PeerJ. https://doi.org/10.7717/peerj.3015

Ioos, S., Mallet, H. P., Leparc Goffart, I., Gauthier, V., Cardoso, T., \& Herida, M. (2014). Current Zika virus epidemiology and recent epidemics. Medecine et Maladies Infectieuses. https://doi.org/10.1016/j.medmal.2014.04.008

K.A.G., C., I., M., I., M., F., M., Y., M., V., F., ... J., M. (2017) Myocarditis, heart failure and arrhythmias in patients with zika Journal of the American College of Cardiology. https://doi.org/10.1016/S0735-1097(17)34295-X LK http://sfx.library.uu.nl/utrecht?sid=EMBASE\&issn=07351097\&id=do i: $10.1016 \% 2 F S 0735-1097 \% 2817 \% 2934295$ -

$\mathrm{X} \&$ atitle $=$ Myocarditis $\% 2 \mathrm{C}+$ heart + failure + and + arrhythmias + in + patie nts+with+zika\&stitle=J.+Am.+Coll.+Cardiol.\&title=Journal+of+the+ American + College + of + Cardiology $\&$ volume $=69 \&$ issue $=11 \&$ spage $=9$ 06\&epage $=\&$ aulast $=$ Carta\&aufirst $=$ Karina + Auristela + Gonzalez \&auin it $=$ K.A.G. $\&$ aufull $=$ Carta $+K \cdot$ A.G. $\&$ coden $=\& i s b n=\& p a g e s=906-$ \&date $=2017 \&$ auinit $1=$ K\&auinitm $=$ A.G.

Kim, K., \& Shresta, S. (2016). Neuroteratogenic Viruses and Lessons for Zika Virus Models. Trends in Microbiology. https://doi.org/10.1016/j.tim.2016.06.002

Nhan, T. X., \& Musso, D. (2015). Emergence of the Zika virus TT Emergence du virus Zika. Virologie.

P., B., G.A., C., A.M., S., M., W., P.C., de S., A., N., ... Jaenisch T. AO Brasil, P. O. http://orcid. org/000.-0001-9555-7976. (2016). Zika Virus Outbreak in Rio de Janeiro, Brazil: Clinical Characterization, Epidemiological and Virological Aspects. PLoS Neglected Tropical Diseases.

Rasmussen, S. A., Jamieson, D. J., Honein, M. A., Ph, D., \& Petersen, L. R. (2016). Spe ci a l R e p or $t$ Zika Virus and Birth Defects - Reviewing the Evidence for Causality.

Rather, I. A., Lone, J. B., Bajpai, V. K., Park, Y., \& Park, Y. (2017). Zika Virus Infection during Pregnancy and Congenital Abnormalities. 8(April), 1-7. https://doi.org/10.3389/fmicb.2017.00581

Rogéria, S., Moura, M., Rabello, L. P., Gonzaga, C. E., Malinger, G., Ximenes, R., ... Jr, O. C. F. (2016). Congenital Zika Virus Infection Beyond Neonatal Microcephaly. 73(12), 1407-1416. https://doi.org/10.1001/jamaneurol.2016.3720

Schuler-Faccini, L., Ribeiro, E. M., Feitosa, I. M. L., Horovitz, D. D. G., Cavalcanti, D. P., Pessoa, A., ... Sanseverino, M. T. V. (2016) Possible Association Between Zika Virus Infection and Microcephaly - Brazil, 2015. MMWR. Morbidity and Mortality Weekly Report. https://doi.org/10.15585/mmwr.mm6503e2er

Schwartzmann, P. V., Ramalho, L. N. Z., Neder, L., Vilar, F. C., AyubFerreira, S. M., Romeiro, M. F., ... Simões, M. V. (2017). Zika Virus Meningoencephalitis in an Immunocompromised Patient. Mayo Clinic Proceedings. https://doi.org/10.1016/j.mayocp.2016.12.019

Shan, C., Xie, X., Barrett, A. D. T., Garcia-Blanco, M. A., Tesh, R. B., Vasconcelos, P. F. D. C., ... Shi, P. Y. (2016). Zika Virus: Diagnosis, Therapeutics, and Vaccine. ACS Infectious Diseases. 
https://doi.org/10.1021/acsinfecdis.6b00030

Shapiro-Mendoza, C. K., Rice, M. E., Galang, R. R., Fulton, A. C. VanMaldeghem, K., Prado, M. V., ... Krishnasamy, V. (2017). Pregnancy Outcomes After Maternal Zika Virus Infection During Pregnancy - U.S. Territories, January 1, 2016-April 25, 2017. MMWR. Morbidity and Mortality Weekly Report. https://doi.org/10.15585/mmwr.mm6623e1

Tappe, D., Rissland, J., Gabriel, M., Emmerich, P., Günther, S., Held, G., ... Schmidt-Chanasit, J. (2014). First case of laboratory-confirmed zika virus infection imported into Europe, November 2013. Eurosurveillance.

7917.ES2014.19.4.20685

Venturi, G., Zammarchi, L., Fortuna, C., Remoli, M. E., Benedetti, E.,
Fiorentini, C., ... Bartoloni, A. (2016). An autochthonous case of zika due to possible sexual transmission, Florence, Italy, 2014 Eurosurveillance. $\quad$ https://doi.org/10.2807/15607917.ES.2016.21.8.30148

Villamil-Gómez, W. E., Ramirez-Vallejo, E., \& Rodriguez-Morales, A. J. (2018). Cardiac Compromise in Zika Virus Infection. Mayo Clinic Proceedings. https://doi.org/10.1016/j.mayocp.2017.12.006

Wu, Y., Cui, X., Wu, N., Song, R., Yang, W., Zhang, W., ... An, J. (2017). A unique case of human Zika virus infection in association with severe liver injury and coagulation disorders. Scientific Reports. https://doi.org/10.1038/s41598-017-11568-4 